SCIREA Journal of Health

http://www.scirea.org/journal/PMH

August 29, 2021

Volume 5, Issue 4, August 2021

\title{
Nursing students' knowledge, attitude and willingness toward the elderly care: A cross-sectional study
}

\author{
Siping Wang*, Lulu Yan, Shanshan Huang, Yan Li, Xianlong Wang \\ School of Nursing, Guangdong Lingnan Institute of Technology, China. \\ *Corresponding author: Siping Wang, master, assistant. Affiliations: School of Nursing, \\ Guangdong Lingnan Institute of Technology. Address(present address): No.492 Daguan \\ middle road, Dongpu, Tianhe, Guanghzou, Guangdong, China, 510663. E-mail: \\ xn_spring@163.com
}

\begin{abstract}
Background: China's aging population is accelerating, and a large number of professional nursing talents need to be trained to improve the quality of care for the elderly. However, there is a shortage of elderly caregivers in China. The aim of the study is to investigate higher vocational nursing students' attitudes toward the elderly and knowledge and willingness of geriatric nursing service.

Methods: A total of 1075 nursing students were recruited between December 2019 to January 2020 in University. The nursing students' basic information, attitude towards the elderly, willingness and knowledge toward elderly care were investigated with a self-designed questionnaire. The correlation between nursing students engaged in elderly service willingness, attitude towards the elderly, and knowledge of aging services were analyzed by Spearman rank correlation coefficient analysis.
\end{abstract}


Results: $61.0 \%$ of the students held negative attitude towards the elderly. $43.6 \%$ of the students were willing to engage in elderly nursing work. $76.0 \%$ of students generally understand the current state of aging in China. $51.6 \%$ of students expect salary to be above 8000 RMB. $49.5 \%$ of the students think that the development prospects of elderly care services are very good. The attitude of nursing students was negatively correlated with their willingness $(r=-0.081, \quad P=0.012), \quad$ knowledge was positively correlated with their willingness $(r=0.367, P<0.001)$, but negatively correlated with their attitude $(r=-0.083$, $P=0.010)$.

Conclusions: Higher vocational nursing students had negative attitudes towards older people, cognition of elderly care service was insufficient, and the willingness to engage in geriatric care services was at the middle and lower levels.

Keywords: Higher vocational; Nursing students; Elderly care; knowledge; Attitude; Willingness

\section{Introduction}

With the improvement of the medical level in the world, people's life span is extended, and the aging population is increasing. Data from the World Health Organization were reported that the population aged 65 or older is projected to increase from an estimated 524 million in 2010 to nearly 1.5 billion in 2050, with most of the increase in developing countries[1]. China, the largest developing country, has become the world's fastest-growing elderly population. According to the statistics about World Population Prospects: China's population over 65 will increase from 164 million in 2019 to 339 million in 2100[2].

Aging has brought a lot of health problems, such as the increase of chronic diseases, and the decline of self-care ability, the demands for nursing services for the elderly are increasing[3]. Therefore, the number of nursing staff taking care of the elderly is increasing. To solve these difficult tasks, it is necessary to foster management personnel and professional technical personnel related to the elderly to meet the social demand. However, the shortage of elderly care service talents in present China, the nursing assistant with older, lower education, and poor nursing service quality restrict the development of the elderly care industry in today's society[4,5]. Nurses held coexisting positive and negative attitudes towards aspects of older 
adult care, such as the characteristics of older adults, their care demands or reflected in nurses' approaches to care, which can directly affect the quality of service for the elderly[6]. Nursing students, as one of the important talents of nursing services for elderly in the future, play a significant role in the development of senior care services. The attitude of nursing students towards the elderly will affect their motivation to engage in geriatric care and the quality of care provided to the aging population[7,8].

The attitudes being noted across nursing students towards older people were inconsistent with positive, negative, and neutral attitudes. Students who have a positive attitude towards the elderly are more willing to engage in nursing services[9-11]. However, a study reported that nursing students have moderately positive attitudes toward older people, they show little interest in working with older people[9]. Several studies showed that nursing students had neutral attitudes toward older people[12,13]. The attitude towards older people and knowledge about aging were significantly correlated with care willingness. Studies have shown that improving nursing students' knowledge of aging can improve nursing students' attitudes towards the elderly[11,12,14,15]. For Chinese nursing students, their attitude towards the elderly was at the medium degree, the care willingness of the elderly was at a medium-high level, while the knowledge about aging was at a lower level[16]. The professional education improve attitudes and willingness of nursing students towards caring for older people and provide higher quality care services for the elderly the quality of nursing services[17,18].

At present, China has expanded the enrollment plan of higher vocational nursing major to cultivate excellent professional talents with high skills and love for elderly care and reserve strength for the development of China's elderly care. However, there are few studies on attitude toward the elderly and willingness, knowledge for elderly nursing service in this population, and the existing research sample size is small. Moreover, students' attitude towards the elderly and their willingness to engage in geriatric care services will affect the employment stability of nurses in the future. Thus, the purpose of this study is to understand the intention of higher vocational college nursing students to engage in geriatric care services and their cognition of geriatric care services through a cross-sectional survey, analyze the reasons behind this situation, and provide a reference for further intervention. 


\section{Methods}

\section{Population}

This was a cross-sectional study in school of nursing. Using convenience sampling method, higher vocational nursing student from the first to third year were selected as the research objects to examine the knowledge and willingness of nursing students to elderly care service, and attitude toward older people. Before the interview, trained interviewer explain the purpose, significance, and content of the research to participants, and ensure that the participants voluntarily participate in the investigation and informed consent. Questionnaires are distributed and collected on-site to ensure the validity of questionnaires. The sample size was calculated by the sample size calculation formula of cross-sectional study: $\mathrm{n}=\mathrm{Z}^{2}{ }_{1-\mathrm{a} / 2} / \delta^{2} \times \mathrm{p} \times(1-\mathrm{p})$. Allowable error was $3 \%, P$ value referring to previous research was 0.6 . Considering the rejection rate and the effectiveness of the questionnaire, expanded by $5 \%$. Thus, a total of 1,075 questionnaires are issued, and the effective response rate is $91.0 \%$.

\section{Measurement}

This study includes four parts: students' basic information, attitude towards the elderly, and knowledge and willingness of services for the elderly. The basic information of the students is as follows: age, gender, homeplace, whether the one-child, academic year, nursing major is your first choice for the college entrance examination, have you ever lived with an elderly person, the length of time you live with an elderly person, relationship with an elderly person, family attitudes towards the elderly, experience of being cared for by the elderly, experience of caring for the elderly. The Kogan's Attitudes toward Older People Scale (KAOP) was used to examine attitude toward the elderly[19]. Due to this scale has been widely used to evaluate attitudes toward older people among medical and nursing students at a medical university[20-22]. The Cronbach's a of the scale in this study was 0.934, with a good reliability. The Kaiser-Meyer-Olkin (KMO) value was 0.949 and findings of Bartlett's test of sphericity were significant $(P<0.001)$, with good validity. Part of knowledge of geriatric care service on the current situation of the aging population in China, the monthly salary that nursing students expect to engage in nursing service, and the view of nursing students on the prospect of nursing service work. Part of the willingness to engage in geriatric care service includes 12 items, and each item is divided into three categories: willingness, unwillingness and uncertain. 


\section{Ethical Considerations}

The ethical approval is exempted by the ethics committee at Guangdong Lingnan Institute of Technology. in this study. Because questionnaires belongs to the study of public behavior, research data of subjects not retain identity information, research information will not allow the participants to assume the risk of civil or criminal liability, and the subjects' state of the economy, employment ability or reputation will not cause damage. All the students who enrolled in this study voluntarily responded to these questionnaire and obtain written informed consent. The confidentiality and anonymity of students' information were considered in this study.

\section{Statistical analysis}

The reliability and validity of the scale were verified by factor analysis and reliability analysis. Qualitative data were expressed as frequency and percentage, while quantitative data were expressed as mean \pm standard deviation. Using the Spearman rank correlation coefficient analysis, the correlation between nursing students engaged in elderly service willingness, attitude towards the elderly, and cognitive aging services were analyzed. All data were statistically analyzed using the SPSS 13.0 software package(SPSS, Inc., Chicago, IL). A bilateral $P$ value $<0.05$ was considered statistically significant.

\section{Results}

\section{Basic information of the student}

A total of 973 students were investigated in this study. Sophomore students accounted for $55.8 \%$, while junior students accounted for 33.0\%. Female students accounted for $89.9 \%$; Students under 20 years old account for $79.8 \% ; 70.9 \%$ of students whose families are in rural areas; Only children accounted for $15.4 \% ; 82.8 \%$ of students majored in nursing as their first choice when filling in the college entrance examination. $87.7 \%$ had lived with the elderly; $72.6 \%$ of students live with the elderly for more than one year; Students who have a good relationship with the elderly account for 96.4\%; 98.2\%. students whose families have a good attitude toward the elderly; $87.4 \%$ of students were cared for by the elderly; $68.4 \%$ of students had the experience of caring for the elderly(Table 1). 
Table 1 Descriptive statistics for characteristics of the nursing students(n=973)

\begin{tabular}{|c|c|c|c|}
\hline Items & Group & Number & Percentage \\
\hline \multirow[t]{3}{*}{ 1.Academic year of the students } & First year & 109 & 11.2 \\
\hline & Second year & 543 & 55.8 \\
\hline & Third year & 321 & 33.0 \\
\hline \multirow[t]{2}{*}{ 2.Gender } & Male & 98 & 10.1 \\
\hline & Female & 875 & 89.9 \\
\hline \multirow[t]{2}{*}{ 3.Age(year) } & $<20$ & 776 & 79.8 \\
\hline & $\geq 20$ & 197 & 20.2 \\
\hline \multirow[t]{2}{*}{ 4.Homeplace } & Urban & 283 & 29.1 \\
\hline & Rural & 690 & 70.9 \\
\hline \multirow[t]{2}{*}{ 5.Only child } & Yes & 150 & 15.4 \\
\hline & No & 823 & 84.6 \\
\hline \multirow{2}{*}{$\begin{array}{l}\text { 6.Nursing major is your first choice for the college } \\
\text { entrance examination }\end{array}$} & Yes & 806 & 82.8 \\
\hline & No & 167 & 17.2 \\
\hline \multirow[t]{2}{*}{ 7.Have you ever lived with an elderly person } & Yes & 853 & 87.7 \\
\hline & No & 120 & 12.3 \\
\hline \multirow{2}{*}{$\begin{array}{l}\text { 8.The length of time you live with an elderly } \\
\text { person(year) }\end{array}$} & $<1$ & 267 & 27.4 \\
\hline & $\geq 1$ & 706 & 72.6 \\
\hline \multirow{2}{*}{$\begin{array}{l}\text { 9. Relationship with an elderly person (a grandparent or } \\
\text { other relative) }\end{array}$} & $\mathrm{Bad}$ & 938 & 96.4 \\
\hline & Good & 35 & 3.6 \\
\hline \multirow[t]{2}{*}{ 10.Family attitudes towards the elderly } & $\mathrm{Bad}$ & 955 & 98.2 \\
\hline & Good & 18 & 1.8 \\
\hline \multirow[t]{2}{*}{ 11.Experience of being cared for by the elderly } & Yes & 850 & 87.4 \\
\hline & No & 123 & 12.6 \\
\hline \multirow[t]{2}{*}{ 12.Experience of caring for the elderly } & Yes & 666 & 68.4 \\
\hline & No & 307 & 31.6 \\
\hline
\end{tabular}

\section{Students' attitude towards the elderly}

According to the KAOP scores, very negative, slightly negative, negative, slightly positive, positive, very positive of the students' attitudes toward the elderly were shown in Table 2. 
Table 2 Distribution of KAOP scores among nursing students $(n=973)$

\begin{tabular}{lll}
\hline Attitude & Number & Percentage \\
\hline Very negative (34-62 score) & 24 & 2.5 \\
Slightly negative(63-91 score) & 88 & 9.0 \\
Negative (92-119 score) & 594 & 61.0 \\
Slightly positive (120-148 score) & 253 & 26.0 \\
Positive (149-177 score) & 13 & 1.3 \\
Very positive(178-204 score) & 1 & 0.1 \\
\hline
\end{tabular}

\section{Students' knowledge of elderly care services}

In table 3 , Among the students' understanding of the aging population in China, only $15.3 \%$ were very familiar with it, $76.0 \%$ were generally not familiar with it, and $8.7 \%$ were not familiar with it. In terms of the expected monthly salary for elderly care service, $4.2 \%$ of the students expect a monthly salary of less than $4000 \mathrm{RMB}, 44.2 \%$ within $4001-8000 \mathrm{RMB}$, and $51.6 \%$ above 8000 RMB. Among the students' development prospects of engaging in geriatric care services, 49.5 percent of the students think that the development prospects of engaging in geriatric care services are very good, 48.5 percent think that the development prospects are moderate, and 2.0 percent think that the development prospects are poor.

Table 3 Knowledge of senior nursing service among nursing students(n=973)

\begin{tabular}{|l|l|l|l|}
\hline Items & Group & Number(n) & Percentage(\%) \\
\hline Aging population status & much & 149 & 5.3 \\
\hline & average & 739 & 76.0 \\
\hline \multirow{2}{*}{$\begin{array}{l}\text { Monthly salary for geriatric care services } \\
\text { RMB) }\end{array}$} & less & 85 & 8.7 \\
\cline { 2 - 4 } & $4001-8000$ & 41 & 4.2 \\
\hline \multirow{2}{*}{$\begin{array}{l}\text { Prospects for the development of elderly nursing } \\
\text { services }\end{array}$} & better & 430 & 44.2 \\
\cline { 2 - 5 } & genera & 4801 & 51.6 \\
\hline & pooer & 19 & 49.5 \\
\hline
\end{tabular}

\section{Students' willingness to geriatric nursing Service}

In Table $4,43.6 \%$ of the students are willing to engage in geriatric nursing service, $38.5 \%$ are not sure, and $17.9 \%$ are not willing. According to the places engaged in geriatric nursing, $42.2 \%, 45.9 \%$ and $50.6 \%$ of the students were willing to work in geriatric nursing institutions, 
community nursing, and home-based nursing, respectively. According to the content of elderly care work, 44.6 percent of students are willing to serve people over 60 years old. $50.9 \%$ of students were willing to take care of chronic diseases. $52.5 \%$ of students were willing to take care of the elderly in daily life, basic care, rehabilitation, and psychological care; $53.5 \%$ of students were willing to provide hospice care services for the elderly; $54.9 \%$ of students were willing to work with older, less educated carers. When it comes to the fact that old-age care is not a high-paying occupation, only $33.7 \%$ of students are willing to take it; When it comes to working in nursing, it means a different level of personal development.

Table 4 Willingness of senior nursing service among nursing students(n=973/\%)

\begin{tabular}{|c|c|c|c|}
\hline Items & willingness & unwillingness & uncertainty \\
\hline 1.Work in elderly care. & $424(43.6)$ & 174(17.9) & $375(38.5)$ \\
\hline 2. Work in a nursing home. & $411(42.2)$ & $205(21.1)$ & $357(36.7)$ \\
\hline 3. Work in community nursing work. & $447(45.9)$ & $185(19.0)$ & $341(35.0)$ \\
\hline 4.Care for the elderly at home. & $492(50.6)$ & $176(18.1)$ & $305(31.3)$ \\
\hline 5.Care for people aged 60 and over. & $434(44.6)$ & $205(21.1)$ & $334(34.3)$ \\
\hline $\begin{array}{l}\text { 6.Care for the elderly with many chronic diseases and poor } \\
\text { rehabilitation. }\end{array}$ & $495(50.9)$ & $159(16.3)$ & $319(32.8)$ \\
\hline $\begin{array}{l}\text { 7.Engage in life care, basic nursing, rehabilitation nursing, and } \\
\text { psychological nursing among the elderly. }\end{array}$ & $511(52.5)$ & $152(15.6)$ & $310(31.9)$ \\
\hline 8.Provide hospice care services for the elderly. & $521(53.5)$ & $163(16.8)$ & $289(29.7)$ \\
\hline $\begin{array}{l}\text { 9. Work with most of the nursing staff who are older and less } \\
\text { educated. }\end{array}$ & $534(54.9)$ & $142(14.6)$ & $297(30.5)$ \\
\hline 10.Eldercare is not a high-paying occupation at present. & $328(33.7)$ & $256(26.3)$ & $389(40.0)$ \\
\hline $\begin{array}{l}\text { 11.Working in old-age care means that personal development is } \\
\text { different from that of a hospital nurse. }\end{array}$ & $347(35.7)$ & $241(24.8)$ & $385(39.6)$ \\
\hline $\begin{array}{l}\text { 12.If most of your classmates go to work in the hospital, are you } \\
\text { still willing to work in elderly care? }\end{array}$ & $327(33.6)$ & $236(24.3)$ & $410(42.1)$ \\
\hline
\end{tabular}

\section{Correlation with willingness, attitude, and knowledge}

The attitude of nursing students was negatively correlated with their willingness $(r=-0.081$, $P=0.012)$, knowledge was negatively correlated with attitude $(\mathrm{r}=-0.083, P=0.010)$, and knowledge was positively correlated with the willingness(r $=0.367, P<0.001)$, shown in Table 5. 
Table 5 Correlation between willingness, attitude, and knowledge $(n=973)$

\begin{tabular}{|l|l|l|l|}
\hline Variables & Mean \pm standard deviation & $r$ & $P$ \\
\hline Willingness & $22.81 \pm 8.53$ & $-0.081^{\mathrm{a}}$ & 0.012 \\
\hline Attitude & $5.93 \pm 1.00$ & $-0.083^{\mathrm{b}}$ & 0.010 \\
\hline Knowledge & $128.87 \pm 28.4$ & $0.367^{\mathrm{c}}$ & $<0.001$ \\
\hline
\end{tabular}

a: willingness and attitude; $b$ : attitude and knowledge; c: knowledge and willingness

\section{Discussion}

The training of elderly nursing service talents conforms to the development trend and demand of an aging society. To cultivate excellent and high-quality professional elderly care talents, the first step is to understand the student's knowledge of old-age care, willingness to old-age nursing as a career, and attitude toward the elderly, which further provide pertinent opinions and suggestions on the talent training scheme.

This study showed that nursing students are mainly female, in line with the development of modern nursing, the fact that has been dominated by women[23]. Most students aged within 20 years, their individuality more make public. They like participation of social public affairs, expect to be understanding and identity, like things that are new or even exciting. As long as to cultivate students' interest in professional of geriatric nursing, it can be a positive influence on the future career. However, carrying out the geriatric care course is a huge challenge for schools and teachers. Garbarino et al found that a designated course in gerontology with a service-learning component can markedly improve student attitudes towards working with older adults[24]. According to the survey, most of the students' families are located in the countryside, the family environment was less affluent, And most students are not the only children in their families. To secure a stable job after graduation, nursing should be a more ideal choice for a student or their parents. We found that most of the students in the college entrance examination application of nursing were the first volunteer, students or their parents to the nursing professional development prospects are more recognition and the stable employment after graduation is optimistic.

Most of the students had lived with the elderly for more than one year, which had a good relationship with the elderly, and heir parents had a good attitude towards the elderly. They had the experience of being taken care of by the elderly or taking care of the elderly. This suggests that some students grow up with older people in their stages. Having a certain 
understanding of the physical and psychological conditions of the elderly, to a certain extent, affect students' attitude towards the elderly. Most of the vocational nursing students, account for $60 \%$, had negative attitudes toward older people, which was inconsistent with previous findings of research $[9,11,12,16]$. It was a very bad phenomenon for the development of elderly care, because negative attitudes were directed at the characteristics of older adults, their care demands, or reflected in nurses' approaches to care[6]. It is necessary to change students' attitudes towards the elderly through education. According to previous studies, nursing students could hold positive, negative, neutral attitude toward the elderly, the older the student, the worse the attitude[10]. Rathnayake et al reported that nursing students have moderately positive attitudes toward older people, and living with older people develops positive attitudes of young people toward older people[9]. Liu et al reported that prefer to work with older people and knowledge of aging appeared to be associated with positive attitudes towards older people[11]. Milutinović D et al using Kogan's Attitudes toward Old People Scale found that students had neutral attitudes toward older people[12]. Therefore, appropriate strategies should be developed for students to increase nursing students' positive attitudes toward older adults and actively pay attention to issues related to the elderly.

Results showed that $43.6 \%$ of the students were willing to work in the aged care services, $17.9 \%$ of students were not. It indicated that higher vocational nursing students willing to engage in the work of the old care is low and slightly lower than previous research report of undergraduate students, $69.0 \%$ of students were willing to work in the aged care, $23.5 \%$ were not[25]. Galzignato et al reported that $69.7 \%$ would take care of an older person, with the previous experience with older patients being the most important determinant in positive attitude of students in working with older people[26]. We can see that there is a small difference in willingness between higher vocational students and undergraduate students. Chi et al Willingness of undergraduate nursing students to engage in geriatric nursing Service had neutral to slightly favorable attitudes toward working with older adults[13]. Besides, 38.5\% of the students indicated that they were not sure whether they were willing to engage in geriatric nursing work, which indicated that if teachers of the school could actively guide these students and improve their cognition of geriatric nursing service, their willingness to work on geriatric nursing service might be improved. The specific survey found that about $50 \%$ of the students are willing to work in elderly care institutions, community nursing care and home-based nursing care, service old people (over 60 years) with various chronic diseases, provide living basic nursing, rehabilitation nursing and psychological care for old 
people, offer hospice care for old people, and work with older and less educated nursing assistants. But when it comes to aged care work is not a well-paid career and personal development of order is different from the hospital nurse or when his classmates went to the hospital to work, for the most part, only about $34.3 \%$ of the students are willing to work in the aged care, willingness to drop nearly $15.7 \%$. This suggests that salary and personal development is an important factor of students in the aged care service willingness. Rockers et al also demonstrated that choice of job position was strongly influenced by salary and direct promotion to permanent staff[27]. Therefore, not only to strengthen the development of elderly care services but also should focus on students' career planning, lets the student in old-age nursing career to realize self-value.

According to the survey, $76.0 \%$ of the students generally understand the present situation of population aging in our country, students to understand the present status of the population aging in China is not enough, degree is low. $44.2 \%$ of the students are looking forward to a month in $4001-8000$ yuan, $51.6 \%$ of the students to look forward to paying 8000 yuan of above. From this perspective, the students hope to get a high salary after graduation. So, old-age care institutions according to the local economic level appropriate to improve the salary can attract the students' positive old-age nursing as a career. In students' prospects of aged care services, $49.5 \%$ of the students think in aged care service development prospect is very good, $48.5 \%$ of the students think the development prospects are mediocre. It shows that the students have a vision for the development of elderly care. The aging in China is gradually accelerating. According to the National Bureau of Statistics, China's population aged 60 and above reached 249 million in 2018, accounting for 17.9 percent of the total population, and will exceed 300 million by 2025[28]. In recent years, China has been committed to the development of the combination of medical and nursing home endowment model, and continuously perfect the old-age service system. Combined with the background of the aging population in China, and the pension services after years of exploration and development of aged care services gradually into the new stage, increasing market demand, make nursing students employment and greater development platform[29-31]. Therefore, for students majoring in nursing care services, we should first let students understand the grim situation of the aging population and the development prospect of nursing care, and change students' inherent cognition of nursing care services, such as poor pay, tiring work, poor status and so on.

The attitude of nursing students towards the elderly will, to some extent, affect their 
motivation to engage in geriatric care and the quality of geriatric care services. Students who have a positive attitude towards the elderly are more willing to engage in nursing services. Chi et al reported that nursing students' positive attitudes about older adults can pay more attention to issues related to older adults, and students who have worked with the elderly can predict their willingness to care for older persons[13]. However, the previous study reported that nursing students have moderately positive attitudes toward older people, they show little interest in working with older people[9]. We also found that a positive attitude towards the elderly does not mean a willingness to engage in geriatric care. There is increasing evidence on the correlation between knowledge and attitudes toward older people which suggests that by acquiring better insights into all aspects of aging through their education the students develop more positive attitudes and interest in working with older adults[12]. However, we found that the more students know about aging, the more negative attitudes towards the elderly, and knowledge of aging were positively correlated with their willingness. Zhang et al found that the willingness of nursing students in China to elderly care was at a medium-high level, and their attitude towards the elderly was at a medium degree, while the knowledge about aging was at a lower level[16]. A study showed that the knowledge about aging has no relationship with the attitude, but gratitude plays a mediation role between the knowledge about aging and care willingness[15]. It is reported that nursing students have insufficient knowledge of nursing care for the elderly. However, nursing students have positive attitudes towards caring for the elderly, Perhaps nursing students have misconceptions about caring for older people. So they are less likely to work with older people[32]. Faculty need to ensure that it is adequate personal with expertise in gerontological nursing to advocate for resources to establish a reputable gerontological nursing profile in nursing curriculum and to develop and sustain a positive attitude towards older people nursing among students and staff.

\section{Limitations}

There were several limitations of this study. First, this study only investigated the students of a private higher vocational college, while the students of public vocational colleges were not carried out. Further research could be carried out on students in public vocational colleges. Second, this study is a cross-sectional study. Longitudinal study may be helpful to observe students' attitudes towards the elderly at different times, as well as their willingness and cognition to engage in elderly services. Third, only a descriptive analysis was conducted in this study. Perhaps research on analysis of the influencing factors could propose more 
intervention strategies to improve students' attitude towards the elderly and their willingness and cognition to engage in elderly services.

\section{Conclusions}

This study demonstrated that the higher vocational nursing students in the aged care service intention is in the middle and lower levels, Most of the vocational nursing students had negative attitudes toward older people Besides, Students do not know enough about the current situation of population aging in China, but they agree about the development prospect of elderly care service. Therefore, higher vocational colleges should take effective strategies to improve students' knowledge of aging and geriatric nursing services, students' attitudes towards the elderly and their willingness to engage in geriatric nursing services, and make personal career planning.

\section{Funding}

This work was supported by the Special Fund for Science and Technology Innovation Strategy of Guangdong Province(grant number: pdjh2020b1379) and the Education and Teaching Reform project of Guangdong Vocational Education for the Elderly Care Major(grant number: 2019YL19).

\section{Acknowledgement}

The authors would like to thank all of the participants who took part in this study.

\section{References}

[1] World Health Organization, US National Institute of Aging, 2011. Global health and aging. https://www.who.int/ageing/publications/global_health/en/.

[2] United Nations, 2019. World Population Prospects: The 2019 Revision. https://population.un.org/wpp/Publications/.

[3] Dziechciaż M, Filip R. Biological psychological and social determinants of old age: bio-psycho-social aspects of human aging. Ann Agric Environ Med. 2014;21(4):835-8.

[4] Cui Y, Fan R, Wang YM, Kaye AJ, Kaye AD, Bueno FR, Pei JM. A Changing Healthcare 
System Model: The Effectiveness of Knowledge, Attitude, and Skill of Nursing Assistants Who Attend Senile Dementia Patients in Nursing Homes in Xi'an, China - A Questionnaire Survey. Ochsner J. 2014;14(3):328-334.

[5] Jia Q, Wang X, Yu X, Li Z, Che X, Shen J. Hand Hygiene Compliance and Influencing Factors Among Nursing Assistants in Nursing Homes. J Gerontol Nurs. 2021;47(4):45-52.

[6] Rush KL, Hickey S, Epp S, Janke R. Nurses' attitudes towards older people care: An integrative review.J Clin Nurs. 2017;26(23-24):4105-4116.

[7] Che CC, Chong MC, Hairi NN. What influences student nurses' intention to work with older people? A cross-sectional study. Int J Nurs Stud. 2018;85:61-67.

[8] Hsu MHK, Ling MH, Lui TL. Relationship Between Gerontological Nursing Education and Attitude Toward Older People. Nurse Educ Today. 2019;74:85-90.

[9] Rathnayake S, Athukorala Y, Siop S. Attitudes toward and willingness to work with older people among undergraduate nursing students in a public university in Sri Lanka: A cross sectional study. Nurse Educ Today. 2016;36:439-44.

[10] Darling R, Sendir M, Atav S, Buyukyilmaz F. Undergraduate nursing students and the elderly: An assessment of attitudes in a Turkish university. Gerontol Geriatr Educ. 2018;39(3):283-294.

[11] Liu YE, Norman IJ, While AE. Nurses' attitudes towards older people: a systematic review. Int J Nurs Stud. 2013 Sep;50(9):1271-82.

[12] Milutinović D, Simin D, Kacavendić J, Turkulov V. KNOWLEDGE AND ATTITUDES OF HEALTH CARE SCIENCE STUDENTS TOWARD OLDER PEOPLE. Med Pregl. 2015;68(11-12):382-6.

[13] Chi MJ, Shyu ML, Wang SY, Chuang HC, Chuang YH. Nursing Students' Willingness to Care for Older Adults in Taiwan. J Nurs Scholarsh. 2016;48(2):172-8.

[14] Ridgway V, Mason-Whitehead E, McIntosh-Scott A. Visual perceptions of ageing; A longitudinal mixed methods study of UK undergraduate student nurses' attitudes and perceptions towards older people. Nurse Educ Pract. 2018;33:63-69.

[15] Garbrah W, Kankkunen P, Välimäki T. Gerontological nurse teachers' abilities and influence on students' willingness in older people nursing: A cross-sectional, correlational survey. Nurse Educ Today. 2020;90:104461.

[16] Zhang S,Liu YH,Zhang HF, Meng LN,Liu PX. Determinants of undergraduate nursing students' care willingness towards the elderly in China: Attitudes, gratitude and knowledge. Nurse Educ Today. 2016; 43:28-33.

[17] Wade S. Promoting quality of care for older people: developing positive attitudes to working with older people. J Nurs Manag. 1999 Nov;7(6):339-47.

[18] Tufan F, Yuruyen M, Kizilarslanoglu MC, Akpinar T, Emiksiye S, Yesil Y, et al. Geriatrics education is associated with positive attitudes toward older people in internal medicine residents: a multicenter study. Arch Gerontol Geriatr. 2015;60(2):307-10. 
[19] KOGAN N. Attitudes toward old people in an older sample. J Abnorm Soc Psychol. 1961;62:616-22.

[20] Bakan AB,Arli SK,Varol E. Identification of nursing students' attitudes toward older people.Contemp Nurse.2018;21:1-9.

[21] Alshehry AS, Almazan JU, Alquwez N. Influence of Religiosity on the Saudi Nursing Students' Attitudes Toward Older People and Perceptions on Elderly Care. J Relig Health.2020;59(6):2701-2714.

[22] Ghimire S, Shrestha N, Callahan KE, Nath D, Baral BK, Lekhak N, Singh DR. Undergraduate nursing students' knowledge of aging, attitudes toward and perceptions of working with older adults in Kathmandu Nepal. Int J Nurs Sci. 2019;6(2):204-210.

[23] Arif S, Khokhar S. A historical glance: Challenges for male nurses. J Pak Med Assoc. 2017;67(12):1889-1894.

[24] Garbarino JT, Lewis LF. The impact of a gerontology nursing course with a service-learning component on student attitudes towards working with older adults: A mixed methods study. Nurse Educ Pract. 2020;42:102684.

[25] Li J and Wang HM. Cross-sectional study on the willingness of undergraduate nursing students to engage in geriatric nursing and related factors. Health vocational education.2019;37(21),135-137.

[26] Galzignato S, Veronese N, Sartori R. Study of the attitudes and future intentions of nursing students towards working with older people: an observational study. Aging Clin Exp Res. 2021.

[27] Rockers PC, Jaskiewicz W, Kruk ME, et al. Differences in preferences for rural job postings between nursing students and practicing nurses: evidence from a discrete choice experiment in Lao People's Democratic Republic. Hum Resour Health. 2013;11:22.

[28] Healthy China Action Promotion Committee. Healthy China Initiative (2019-2030). http://www.gov.cn/xinwen/2019-07/15/content_5409694.htm.

[29] Hu B, Li B, Wang J, Shi C. Home and community care for older people in urban China: Receipt of services and sources of payment. Health Soc Care Community. 2020;28(1):225-235.

[30] Li L, Yuan J, Ning Y, Shao Q, Zhang J. Exploring Space Management Goals in Institutional Care Facilities in China. J Healthc Eng. 2017;2017:6307976.

[31] Pan H, Dury S, Duppen D, Lehto V, Wang R, Donder L. Social Participation in Older Adults after Relocation to Long-Term Care Institutions in China: A Qualitative Study. J Community Health Nurs. 2020;37(3):164-176.

[32] Abudu-Birresborn D, McCleary L, Puts M, Yakong V, Cranley L. Preparing nurses and nursing students to care for older adults in lower and middle-income countries: A scoping review. Int J Nurs Stud. 2019;92:121-134. 